\title{
Retraction Note to: Plant slope reconstruction in plain area based on multi-core ARM and music teaching satisfaction
}

\author{
Zhihui Luo ${ }^{1}$
}

Published online: 3 November 2021

(c) Saudi Society for Geosciences 2021

Retraction Note to: Arabian Journal of Geosciences (2021) 14: 1651 https://doi.org/10.1007/s12517-021-08020-3

The Editor-in-Chief and the Publisher have retracted this article because the content of this article is nonsensical. The peer review process was not carried out in accordance with the Publisher's peer review policy. The author has not responded to correspondence regarding this retraction.

The original article can be found online at https://doi.org/10.1007/ s12517-021-08020-3.

Zhihui Luo

cqlzh113@126.com

1 College of Educational Science, Yangzhou University, Yangzhou, China 